\title{
The Microstructure of a Multielement Nanostructured (TiZrHfVNbTa)N Coating and Its Resistance to Irradiation with $\mathrm{Au}^{-}$Ions
}

\author{
A. D. Pogrebnjak ${ }^{a *}$, I. V. Yakushchenko ${ }^{a}$, O. V. Bondar ${ }^{a}$, O. V. Sobol' ${ }^{b}$, \\ V. M. Beresnev ${ }^{c}$, K. Oyoshid ${ }^{d}$, H. Amekura ${ }^{d}$, and Y. Takeda ${ }^{d}$ \\ ${ }^{a}$ Sumy State University, 40007 Sumy, Ukraine \\ ${ }^{b}$ National Technical University Kharkiv Polytechnic Institute, 61002 Kharkiv, Ukraine \\ ${ }^{c}$ Karazin Kharkiv National University, 61022 Kharkiv, Ukraine \\ ${ }^{d}$ National Institute for Material Science, 305-0003 Tsukuba, Japan \\ *e-mail: alexp@i.ua \\ Received June 11, 2015
}

\begin{abstract}
The formation of a phase with a FCC lattice of the $\mathrm{NaCl}$ structure type is observed following the deposition of a multielement nanostructured (TiZrHfVNbTa) N coating. An increase in pressure results in a change in the preferred orientation of crystallite growth from the [100] axis perpendicular to the growth plane to [111]. The implantation of negative $\mathrm{Au}^{-}$ions with a dose of $1 \times 10^{17} \mathrm{~cm}^{-2}$ and a concentration of 2.1 at $\%$ leads to the formation of a disordered polycrystalline structure with no preferred orientation of the FCC phase, reduces the size of nanocrystallites from 8 to $1-3 \mathrm{~nm}$ in a layer with a depth of up to $30-35 \mathrm{~nm}$, and increases the nanohardness to $33.0 \mathrm{GPa}$. The large difference in atomic radii of refractory metals and the reduction in the size of nanograins in the coating contribute to an increase in hardness $(51 \mathrm{GPa})$.
\end{abstract}

DOI: $10.1134 / \mathrm{S} 1063785015110085$

The past decade saw the development of a novel class of high-entropy alloys (HEAs) that incorporate at least five major elements with an atomic concentration of 5-35\%. HEAs are notable for the fact a singlephase stable solid substitutional solution (primarily with an FCC or a BCC lattice) that exhibits thermodynamical stability and high strength is formed within them [1-3]. The synthesis of nitrides or carbides from HEAs is also a relevant problem, since they are more resistant to oxidation and exhibit higher wear resistance, corrosion resistance, hardness, and ductility than "pure" HEAs. The problem of determining the limits of resistance of nitrides precipitated from HEAs to implantation is also of academic and practical importance. We chose negative $\mathrm{Au}^{-}$ions with a dose of up to $1 \times 10^{17} \mathrm{~cm}^{-2}$ and a kinetic energy of $60 \mathrm{keV}$ for our experiments. This choice was determined by the fact that the majority of elements of the studied highentropy coating $(\mathrm{Ti}, \mathrm{Zr}, \mathrm{Hf}, \mathrm{Nb}$, and $\mathrm{Ta}$ ) do not interact with gold with the synthesis of intermetallides. Thus, the aim of the present study was to investigate the microstructure and mechanical properties of multicomponent nitride coatings and their resistance to ion irradiation.

The phase composition of coatings was determined using DRON-3M (in $\mathrm{Cr} K_{\alpha}$ radiation) and RINT-
$2500 \mathrm{VX}$-ray diffractometers. Two methods of analysis of the elemental composition were used: EDX microanalysis with a JEOL-7000F (Japan) SEM and SIMS analysis with an ULVAC-PHI TRIFT $\mathrm{V}$ nanoTOF (Physical Electronics, Inc., Japan) time-of-flight spectrometer. The surface of multicomponent coatings, their elemental composition, and the distribution of elements over their surface were also studied using a JSM-6010 LA (JEOL, Japan) SEM with an energydispersive spectrometer. Microhardness measurements were performed using a REVETEST (Switzerland) device, and nanohardness and the Young's modulus were determined with a Triboindentor TI950 (HYSITRON Inc.) device in the dynamic mode.

The coatings were obtained by pulsed vacuum arc deposition [4] in the process of evaporation of a target, which was made from a high-entropy TiZrHfVNbTa alloy, in nitrogen atmosphere with the purpose of increasing the energy of the ion-plasma stream at the moment of deposition and enhancing the adhesion of coating to the surface in order to produce a more disperse coating structure. Coatings with a thickness of up to $8 \mu \mathrm{m}$ were deposited onto steel disks with a diameter of $45 \mathrm{~mm}$ and a thickness of $4 \mathrm{~mm}$. The deposition parameters were chosen based on the results of analysis of similar coatings $[5,6] ; P_{\mathrm{N}}$ is the nitrogen atmosphere pressure in the process of depo- 


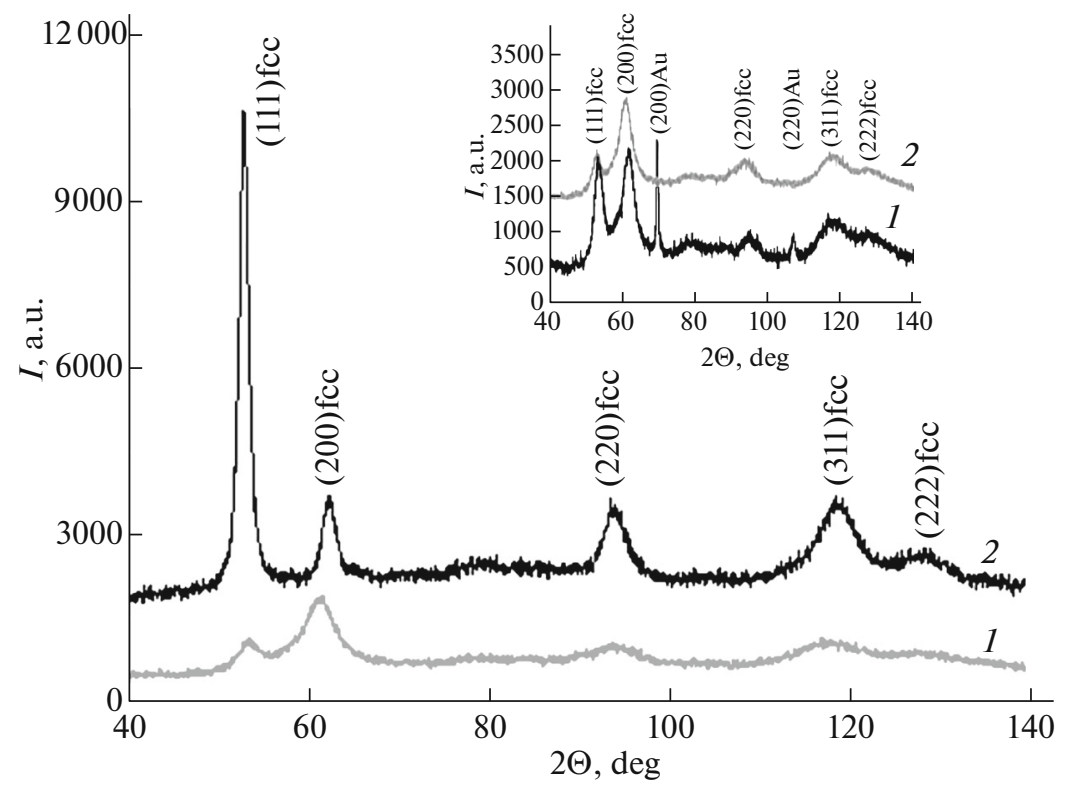

Fig. 1. Fragments of diffraction spectra of (TiZrHfVNbTa) N coatings obtained under $P_{\mathrm{N}}=3 \times 10^{-4}$ Torr $(1)$ and $P_{\mathrm{N}}=3 \times$ $10^{-3}$ Torr (2). Spectra obtained under $P_{\mathrm{N}}=3 \times 10^{-4}$ Torr after irradiation with negative $\mathrm{Au}^{-}$ions at $(1)$ a low incidence angle of $2^{\circ}$ and (2) a large constant incidence angle of $10^{\circ}$ are shown in the inset.

sition. Negative $\mathrm{Au}^{-}$ions were produced by a Csassisted source of heavy ions of the plasma-atomized type $[7,8]$. An increase of pressure resulted in a significant increase in the nitrogen concentration in the coating and a reduction in the concentration of such elements as $\mathrm{Ti}, \mathrm{Nb}$, and $\mathrm{V}$ (i.e., resulted in a change in the concentration of elements in the coating with respect to the cast cathode composition). The results of EDS, RBS, and PIXE studies showed that the gold content was $2.1-2.2$ at $\%$ at projected range of $\mathrm{Au}^{-}$ ions $R_{p} \approx 34 \mathrm{~nm}$.

Figure 1 shows the XRD spectra of high-entropy coatings obtained under different nitrogen pressures in the process of deposition. A phase with a FCC lattice was formed as the main crystalline one. This is typical for the structure of a nitride of a multielement alloy. The average size of crystallites of the FCC phase in the coatings obtained under a low pressure of $3 \times 10^{-4}$ Torr was estimated based on the Scherrer equation at about $8 \mathrm{~nm}$. A preferred orientation of crystallite growth with the (200) plane parallel to the surface (the [100] texture axis was perpendicular to the surface) was also formed. Spectrum 2 (see Fig. 1) that corresponds to a coating obtained under a relatively high pressure of $3 \times$ $10^{-3}$ Torr is fundamentally different in that a preferred orientation of the (111) plane parallel to the growth plane emerged in it (this was evidenced by a considerable increase in the relative intensity of peaks from the corresponding plane). The average size of crystallites of the FCC phase of the coating deposited under the indicated high pressure was increased significantly and equaled $17-20 \mathrm{~nm}$.
$\mathrm{Cr} K_{\alpha}$ radiation with a wavelength of $0.2285 \mathrm{~nm}$ was used to investigate the effect of implantation of $\mathrm{Au}^{-}$ ions. The informative layer depth under such irradiation with an angle of incidence of $2^{\circ}$ was about $70 \mathrm{~nm}$ (this is comparable to projected range $R p \approx 34 \mathrm{~nm}$ ). Diffraction spectra measured at an incidence angle of $10^{\circ}$ (such spectra provide the data on a volume of material with a thickness of $0.5 \mu \mathrm{m}$ ) and at an angle of $2^{\circ}$ (providing the data on the state of the surface layer with a thickness of up to $70 \mathrm{~nm}$ ) are shown in the inset of Fig. 1. In the near-surface region, the implantation of negative $\mathrm{Au}^{-}$ions produced the most pronounced disordering effect and resulted in the formation of a polycrystalline structure with no preferred orientation and the emergence of peaks corresponding to the planes of implanted gold. Comparison of sizes of crystallites in the implanted layer showed that their average size was reduced from $7.2 \mathrm{~nm}$ at an informative layer depth of $0.5 \mu \mathrm{m}$ to $3 \mathrm{~nm}$ (or lower) at shallower depths.

Figure 2 shows the dependences of nanohardness and the relative Young's modulus on the depth of penetration of a Berkovich pyramid [3, 5] into sample no. 6 in the case of dynamic indentation (the load on the indenter was varied from 500 to $10000 \mu \mathrm{N})$. The nanohardness was increased to almost $33 \mathrm{GPa}$ in the implanted layer with a thickness of $30-35 \mathrm{~nm}$ and then leveled off gradually down to a penetration depth of $80 \mathrm{~nm}$. An increase in the plasticity index in the implanted region $(H / E \geqslant 0.1)$ is indicative of excellent wear resistance. In accordance with [9], the hardness of samples subjected to the implantation of heavy $\mathrm{Au}^{-}$ 


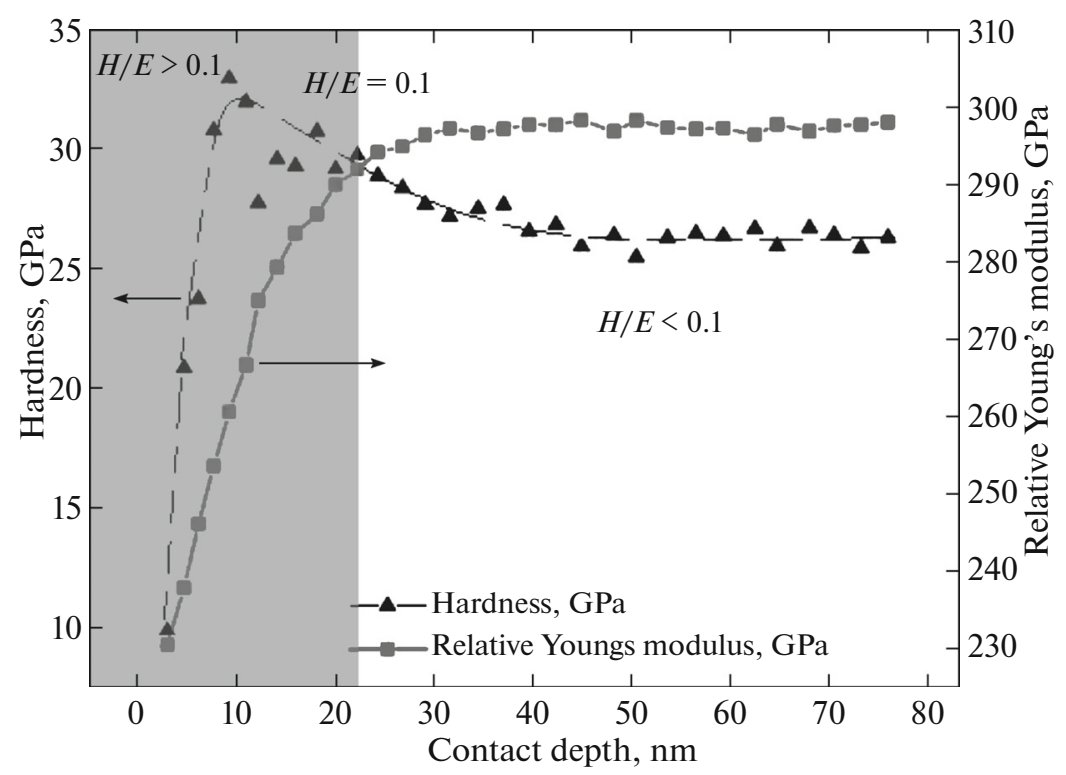

Fig. 2. Dependences of nanohardness and the relative Young's modulus on the depth of penetration of the indenter into sample no. 6 .
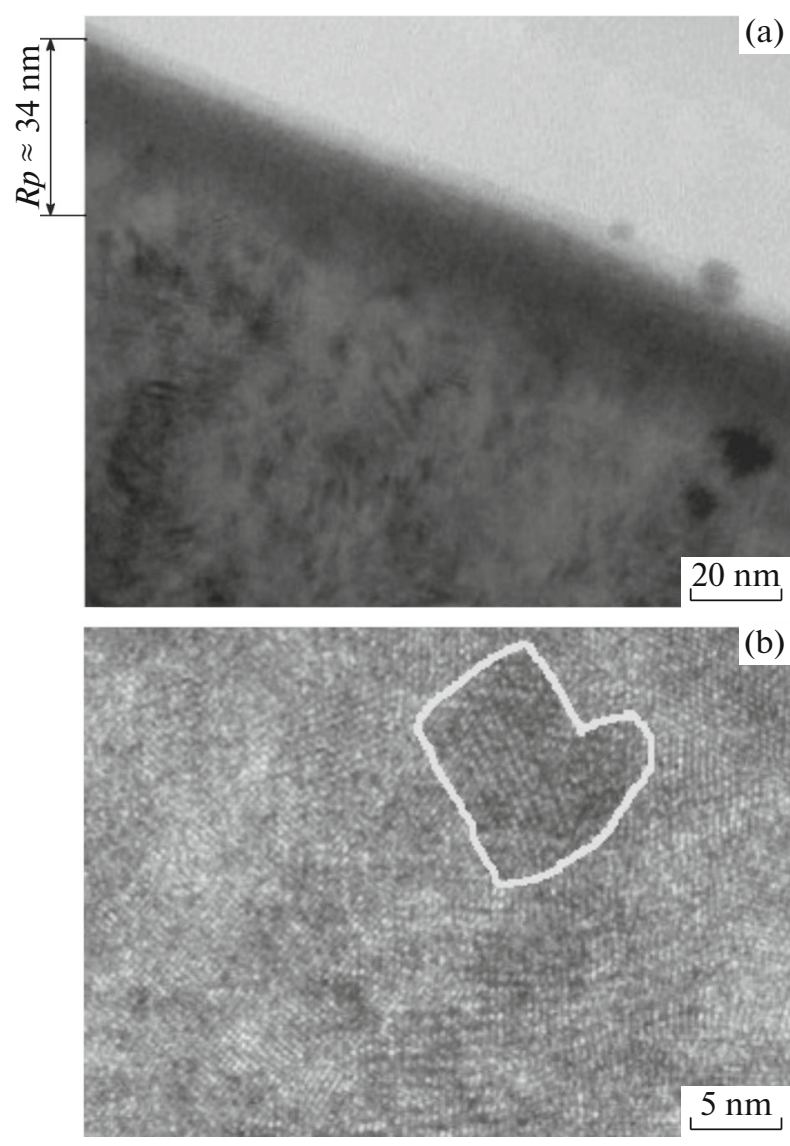

Fig. 3. TEM images of cross-section of a (TiZrHfVNbTa)N coating: (a) the near-surface layer with implantation depth indicated and (b) a fragment of this coating located at a depth of about $50 \mathrm{~nm}$. ions was increased by $15-20 \%$ and their plasticity index exceeded 0.1. The Vickers hardness values are higher than the Young's modulus and nanohardness for coatings made from HEA nitrides, since nanoindentation experiments are conducted in the dynamic mode, while the value of Vickers hardness is measured in the static mode.

It is common knowledge that $\mathrm{Au}^{-}$ions have a high sputtering ratio $[7,8]$. Accordingly, partial sputtering of $\mathrm{N}$ atoms (due to their weaker bonding) from the surface was observed and defects (vacancy and interstitial loops) were formed [9-14]. Implanted $\mathrm{Au}^{-}$ions in the coating formed nanocrystallites of a "spherical" shape with a size of several nanometers as was the case in the experiments with $\mathrm{Cu}^{-}$and $\mathrm{Au}^{-}$ions implanted into $\mathrm{SiO}_{2}$ in [9]. The efficiency of recombination of point defects in a nanostructured coating is increased near cascades or within them due to the proximity of interfaces (boundaries between nanograins or double and triple junctions of nanograins) [12]. In addition, the volume ratio of boundaries is increased in the process of implantation with heavy ions due to a reduction in the size of nanograins from 8 to $5 \mathrm{~nm}$ (or less). As a result, a disordered polycrystalline structure with no preferred orientation of the FCC phase is formed. Thus, the obtained nanostructured coatings are considerably more resistant to irradiation with $\mathrm{Au}^{-}$ions than single crystals and polycrystals.

Figure 3a shows a fragment of a section of the (TiZrHfVNbTa) $\mathrm{N}$ coating implanted with $\mathrm{Au}^{-}$ions. The surface layer is disordered down to depth $R p \approx$ $34 \mathrm{~nm}$ and has a polycrystalline structure that is close to an amorphous-nanocrystalline one. The structure 
below this layer is nanocrystalline with a nanograin size of about $7 \mathrm{~nm}$ (Fig. 3b). Outlined in white is a nanograin with a size of about $7 \mathrm{~nm}$ located at a depth that exceeds somewhat the implantation depth. One may also note that nanograins in the implanted layer have considerably smaller sizes of $\sim 0.8-1 \mathrm{~nm}$.

The studied nitride high-entropy nanostructured (TiZrHfVNbTa) $\mathrm{N}$ coatings exhibit high hardness values $(51 \mathrm{GPa})$, and their nanohardness is as high as $33.0 \mathrm{GPa}$.

Acknowledgments. This work was supported by two budget projects (nos. 0112U001382 and 0113U000137) and international scientific cooperation (between Sumy State University and the National Institute for Material Science, Tsukuba, Japan) (program no. 514) run by the Ministry of Education and Science of Ukraine.

\section{REFERENCES}

1. Y. Zhang, T. T. Zuo, Z. Tang, M. C. Gao, K. A. Dahmen, P. K. Liaw, and Z. P. Lu, Prog. Mater. Sci. 61, 1 (2014).

2. B. S. Murty, J.-W. Yeh, and S. Ranganathan, HighEntropy Alloys (Butterworth-Heinemann, 2014).

3. A. D. Pogrebnjak, A. A. Bagdasaryan, I. V. Yakushchenko, and V. M. Beresnev, Russ. Chem. Rev. 83 (11), 1 (2014).
4. A. D. Pogrebnjak, D. Eyidi, G. Abadias, O. V. Bondar, V. M. Beresnev, and O. V. Sobol, Int. J. Refract. Met. Hard Mater. 48, 222 (2015).

5. X. Feng, G. Tang, X. Ma, M. Sun, and L. Wang, Nucl. Instrum. Methods Phys. Res., Sect. B 301, 29 (2013).

6. A. D. Pogrebnjak, I. V. Yakushchenko, A. A. Bagdasaryan, O. V. Bondar, R. Krause-Rehberg, G. Abadias, P. Chartier, K. Oyoshi, Y. Takeda, V. M. Beresnev, and O. V. Sobol, Mater. Chem. Phys. 147, 1079 (2014).

7. F. F. Komarov, Ion Implantation into Metals (Metallurgiya, Moscow, 1990) [in Russian].

8. N. Kishimoto, V. T. Gritsyna, Y. Takeda, and C. G. Lee, J. Surf. Sci. 4, 220 (1998).

9. V. Ivashchenko, S. Veprek, A. Pogrebnjak, and B. Postolnyi, Sci. Technol. Adv. Mater. 15, 025007 (2014).

10. V. Braic, A. Vladescu, M. Balaceanu, C. R. Luculescu, and M. Braic, Surf. Coat. Technol. 211, 117 (2012).

11. S.-Y. Chang, S.-Y. Lin, Y.-C. Huang, and C.-L. Wu, Surf. Coat. Technol. 204, 3307 (2010).

12. D.-C. Tsai, Y.-L. Huang, S.-R. Lin, S.-C. Liang, and F.-S. Shieu, Appl. Surf. Sci. 257, 1361 (2010).

13. Z.-C. Chang, D.-C. Tsai, and E.-C. Chen, Mater. Sci. Semicond. Process. 39, 30 (2015).

14. F. Meng and I. Baker, J. Alloys Compd. 645, 376 (2015).

Translated by D. Safin 